\title{
"Life was not all that bad": memories and experiences of kolkhoz life in the Baltic States
}

\author{
Friedrich Kuhlmann ${ }^{1}{ }_{1}$ and Martti Veldi ${ }^{1}$ \\ ${ }^{1}$ Estonian University of Life Sciences, Chair of Landscape Architecture, Tartu, Estonia
}

\begin{abstract}
The physical impact of modernism in the rural landscape and its remains are explored in order both to capture the results of past decisions and the current state of the rural landscapes and to connection these. But if we ask how, have these landscapes evolved over time and what actually remains, we often only look on built remains, artefacts or plans forming the raw material. Instead, we put the focus on the actions of the people living and working there, with their memories, reflections, their past desires and their plans achieved or destroyed. Compared with the built remains of collectivization schemes, many of the actors of the Soviet collectivisation process in the Baltic States are still alive, having a voice and opinions. To capture this involves a survey of case study landscapes and settlements through fieldwork and comparative analysis in order to compare the initial plans with the actual experience of the collectivisation and to relate the built results and spatial patterns to people's memories. The actions that formed and still form the landscape were identified and assessed by qualitative go-along interviews with current and former residents, workers or decision makers in the area to create a "thick description" through which we uncovered everyday life aspects of dwellers or workers. What we found is that far from being a completely negative period, life in the collective farm was not all bad housing improved, people had guaranteed jobs, medical care and education were provided. Young people unaware of politics enjoyed their childhoods and there is some degree of nostalgia remaining, even while the new freedoms and independence of the countries are celebrated (with a centenary in 2018).
\end{abstract}

\section{Introduction}

If we ask: "how important is the impact of the Soviet rural economy on today's everyday life?" we are confronted with a contradictory situation. At present, the cultural landscape of rural Estonia has a post-Soviet appearance, with the agricultural field and forest structure as well as the settlement structure forming the main character of the landscape. In terms of landscape historical research, the remains of the old manors and the farmstead system of the First Estonian republic have been the focus in order to present heritage and reinforce national identity in Estonia. The Soviet collective farm period is often seen as a break, a strange discontinuity in the rural history. To mediate

\footnotetext{
${ }^{1}$ Corresponding author friedrich.kuhlmann@emu.ee
} 
this cultural contradiction the MODSCAPES project seeks to understand Modernist rural landscapes as having developed over time, to be considered as a layer of history and as still having an impact, shaping people's lives for more than two generations in Estonia. The aim is to find out how the modernist rural landscape, in these case study areas, has developed, what is visible and how it is perceived, experienced and endured by the people today. In this paper, we present preliminary results from three Estonian MODSCAPES case study areas at Omedu, Laeva and Viimsi.

The physical impact of Modernism in the rural landscape and the remains of 40 years of collective farming in Estonia are explored in order to capture both the results of past decisions and the current state of the rural landscape. But if we ask, how have these landscapes evolved over time and what actually remains, we often only look at built remains, artefacts or plans as the raw materials for research. In this work, we have focused on the actions of the people living and working there, their memories, reflections, their past desires and whether their plans and hopes were achieved or not.

By understanding the spatial grammar of the landscape as well as perceiving it through different media, other aspects can be revealed which are not visible through visual and structural mapping methods alone. They can be found when we connect these physical characteristics with the active life of people [1]. Compared to the built remains of the collectivization schemes, which are frequently derelict, many of the actors who were workers, settlers or stakeholders in the Soviet collectivisation process are still alive, have a voice and hold different opinions about the era.

The answers to the question how bad was life under the Soviet Occupation in the kolkhoz? if focusing on the stories of places through inhabitants' memories, may challenge the view that everything Soviet was negative yet it needs to be asked, regardless of all the problems connected with subjective statements, and it turns out that life wasn't all that bad in those days.

\section{Methods}

The current state of the Modernist rural landscapes can be captured by comprehensive mapping techniques. Initially, this involves fieldwork and comparative analysis of maps of case study areas in order to understand the processes of collectivisation at different spatial scales across time. These plans can be compared with the actual experience of the collectivisation, and the built results and spatial patterns can be related to local people's memories. Since it is people's actions that have formed and still form the cultural landscape, we can identify and assess such actions by using traditional interview techniques, as well as by employing Go-along interviews, with current and former residents, workers and decision makers from the case study areas.

By uncovering aspects of everyday life and of place-making by residents or workers during the collectivisation era a thick description [2] of each landscape can be assembled in order to identify a Modernist rural identity. As an important anthropological research approach Geertz's concept of thick description explains not only human behaviour but also its context, so that it becomes meaningful to an outsider (a researcher). According to Geertz, cultural analysis should be an interpretative practice tracing the modes and customs in which meaning is qualified [2]. In the context of our research the focus shifts from a distant objectification to a more participatory observation, embedding the researcher in the performance of the setting, where the raw observational material is insufficient.

Thus, to find out how the modernist cultural landscape impacted and continues to imnart the livac of Innal nonnlo an oynorimontal mothndolnew wac davolnnod hy tho 
Estonian MODSCAPES team. We applied different data gathering methods but connected them to each other in a set of steps, collecting and analysing one data which triggers the collection of a further set of data. Firstly, we digitised historical maps as a basis for preparing a series of map layers at the same scale for quantitative spatial comparison (historical GIS [3]). We then collected and interpreted moving images made by videos taken while driving and walking through or around the area (we call this divingin). The final aspect of data collection was carried out in order to discover significant places representing the modernist rural landscape as part of a national heritage as well as capturing aspects of people's life stories as the base for developing identity under this condition. This involved Go-Along interviews with residents and former workers as a means of understanding how the landscape impacted and continues to impact the experiences and perceptions or residents [4].

The Go-along interview method is a valuable approach for meeting the objectives of our research. It builds on ethnographic research methods, described by Pink as sensory ethnography, involving the empathetic engagement of the researcher with practices and places that are important to the people participating in the research. According to Pink, it can also involve interviewing, walking, discussing images or listening to music with them. "Altogether, sensory and ethnographic methods involve the production of meaning in participation with people through a shared activity in a shared place, furthermore producing knowledge with others in movement and through engagement with/in a material, sensory and social environment." [5: 271].

Kusenbach defines the Go-along method as a research tool to "access lived experience on site by connecting place with everyday experience and practices." She notes, that our experience of environment is based on our body, giving perceptual 'place' primacy over abstract 'space'. A perceptual space is actually consisting of places with personal significance, such as actual places but also imagined and remembered ones [6: 455]. Ethnographers and sociologists as well as health researchers have started to explore the potential of this method of field research, but in cultural landscape research it is a fairly new approach, only recently published by a Canadian research team [7]. Elaborating the aforementioned thoughts on spatial experience, they call for an understanding of landscape not only by "being in" it but rather by "moving in and through" it [7: 109].

Go-along interviews ask the interviewer to study the research subject in motion, being conducted at different scales and at different speeds to explore both the activities those movements permit and the spaces in which these take place.

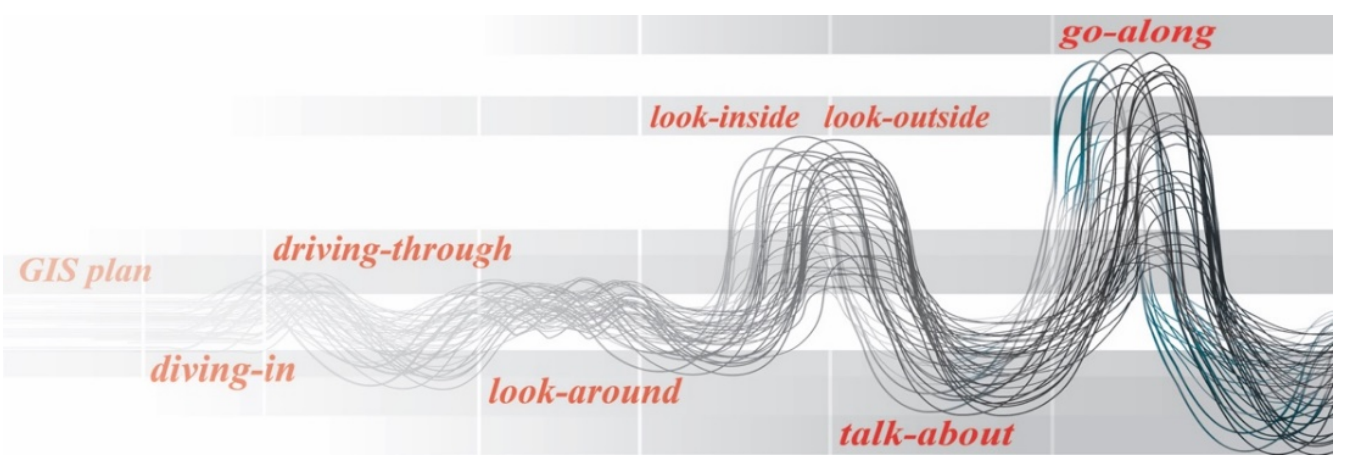

Fig. 1. Research steps. (Source: the authors)

We explored and experienced the case study areas first-hand in the so-called DiveIn step. This was conducted through filming while making verbal comments about route 
and area, built up on the GIS map basis for all the following steps in the research narrative (Fig. 1). In the Drive-Through step we observed the area through filming while recording comments about route and area. The filmed material was then analysed by assessing types of distinctive places or elements that were filmed repeatedly. The LookAround step explored the character of the areas by $360^{\circ}$ surround filming at specific spots, while Look-Inside/Look-Outside steps explored the areas by filming situations representing everyday movement cycles. All locations were identified during the first two steps but could also be adjusted or added later.

The final step of data collection involved Talk-about and Go-along interviews, but for discussing the theoretical and methodological aspects brought up above, only the results of the Go-Along interview will be presented here. In Omedu, the Go-along interview was only performed on foot around the main building complex (the site is too small and impossible to drive around), while in Laeva and Viimsi it was also performed by car because of the large expanse of the collective farm businesses and scattered farmsteads connected to the area.

The results demonstrate three examples from the case study areas, where interviewees were asked to choose their own routes in order to generate stories about their spaces. By overlaying spatialized transcripts on a GIS map, we could identify locations which had specific effects in stimulating recollections and associations. Which places tend to attract people and which are ignored? Which places are of high interest and which ones are not mentioned? The interviews were recorded and transcribed for analysis and synchronized with the spatial and visual data produced by the paths and photographs, creating a qualitative GIS.

\section{Results}

\section{Walking in Omedu}

The Dive-in at the Omedu fishing collective farm formed the basis for all following steps in the research narrative. It was used to develop a first understanding by way of preparing a canvas to paint on. The research team commented continuously on all aspects of the appearance of the area while filming. After conducting the walk, we mapped the positions of each stage. Together with the maps the film material was used for assessing types of distinctive places as well as elements captured multiple times to be focused at the Go-along interviews. The encroachment of the forest has led to the setting of the building complex and the way it would originally have been seen by visitors being enclosed and hidden as opposed to open and visible [8].
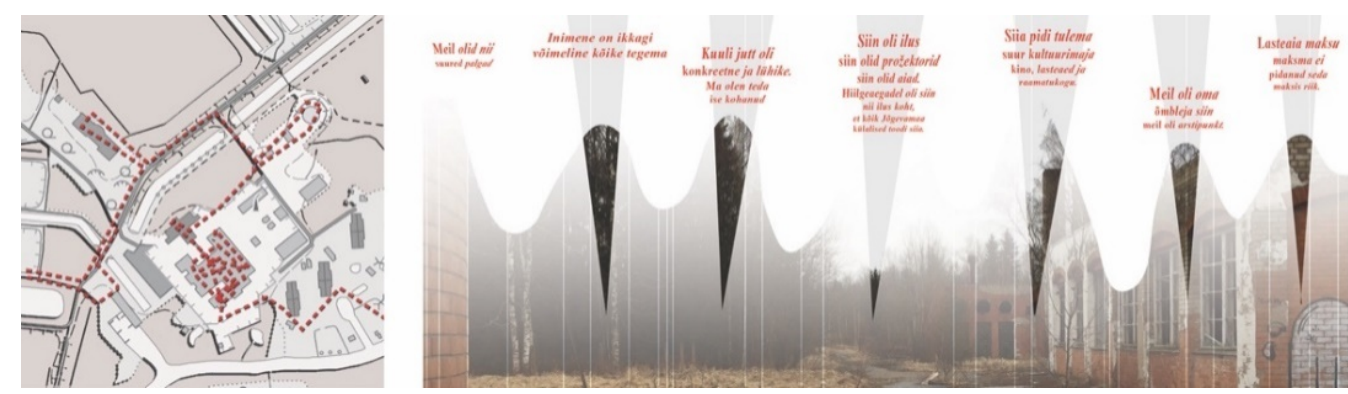

Fig. 2. Go-along conducted in Omedu: Map, route and important quotes. (Source: the authors) 
We interviewed two local women who still live there and who worked in the complex when it was operational, while letting them walk us through different places which mattered to them personally. As we went along with the interviewees they gave us a glimpse into their daily life and routines as workers and settlers. After the interview, we mapped the interview route and places that were telling a story (Fig. 2). Together with the GIS maps the video material was used for analysing the interviews and finding places which strongly represented the abundance of information about Omedu. The women described how good the place was to work at. We illustrate using direct quotes some of the unique and occasionally bizarre aspects surrounding this case study.

They informed us that the site for the kolkhoz was chosen by the powerful chairman of the main kolkhoz Oskar Kuul. The women told us how he pointed at a place on the map and gave the order to build it there without any detailed knowledge of the swampy nature of the site and no logical reason for its location in an unsuitable place.

The interviewee mentioned how they greeted the building of Omedu fish farm in the middle of nowhere in amazement, how the wet forest land was turned into a fish farm:

Why was the fish farm and caviar factory built here in the forest? It once was only forest and meadows, but man is capable of doing everything! The officials of Mustvee wanted the fish farm to be built there and offended Oskar Kuul because he was given the conditions but he showed the officials the place and was willing to build dwelling houses here in the forest and everything else. Oskar Kuul was a straightforward man. Nothing was impossible for him and asphalt was put on the roads in the middle of forest!

After some walking, the interviewee comments with pride on the abandoned fish ponds in the forest, now overgrown with bushes:

Europe's largest fish farm on dry land had to come here with hectares of ponds. Now everything is overgrown with bushes. It turned out that the water was too warm, so it was decided to build a fake caviar factory here. It was beautiful here: there were spotlights, there were gardens. At its greatest times, here was such a beautiful place that all Jõgevamaa guests were brought here. No grass was allowed to grow between the pavement tiles, the order was like in the army. Everything was mowed!

While going along in the office building, the interviewee refers to the money-hole:

The accountant living in this village went to the Rayon centre on pay day and we had a place with a hatch where the salaries were paid (Fig. 3). She came with two plastic bags, bringing the wages of the collective farms. We had so much salary. There was a legend on how the accountant came up with two bags only full of plastic bags:

"Aah, I have so much money! I have so much money!"

But Jõgeva is a small place and nobody ever robbed her.

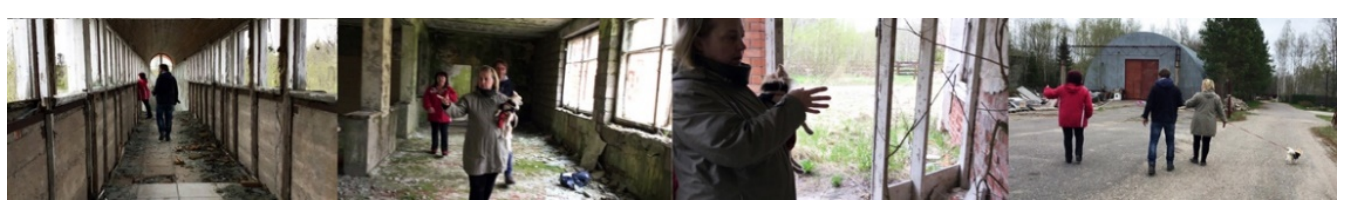

Fig. 3. Go-along conducted in the office building of Omedu. (Source: the authors)

Later the interviewee mentions the unfinished culture house ruin:

This was my grandfather's large forest and we got four hectares back after the collapse of Soviet Union but we simply did not take it. The two-storey cultural house was not completed, the roof beams were already erected, even the party to celebrate its erection was held. But 
everything disappeared, the beams were removed and what can one do with colossal ruins? (Fig. 4). It was supposed to be a large cultural house with a cinema, kindergarten and library. Someone said they did not know what capitalism was during the Soviet era, but we knew! We have lived in the capitalism, in a country in the country. We had our own clothes designers and medical doctors here. We did not have to pay for the kindergarten, it was paid by the state. All the children were taken to the kindergarten without fee.

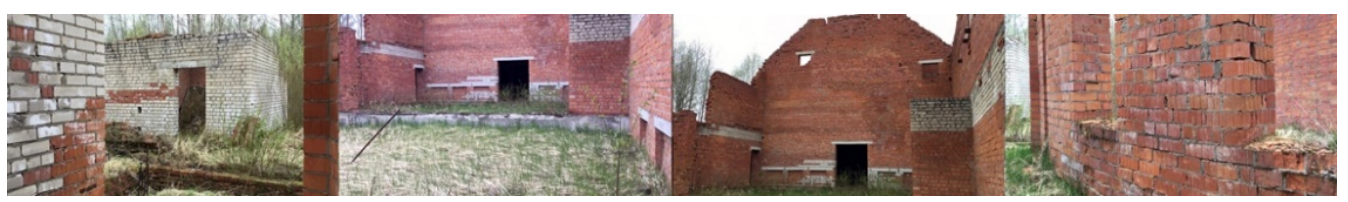

Fig. 4. Stills from the Dive-in of the unfinished culture house. (Source: the authors)

\section{Interview on foot and by car in Laeva}

At the former Laeva Sovkhoz farm, focused on forestry melioration and mechanization of agriculture, we followed one interviewee, a cultural worker today and former inhabitant, into her familiar environments during the Go-along and tracked the places she would go to as a former resident, still remembering the outstanding cultural life that existed at the time (Fig. 5). We identified certain places to conduct short lookinside/look-outside filming, being a good example for the interchangeability of steps.
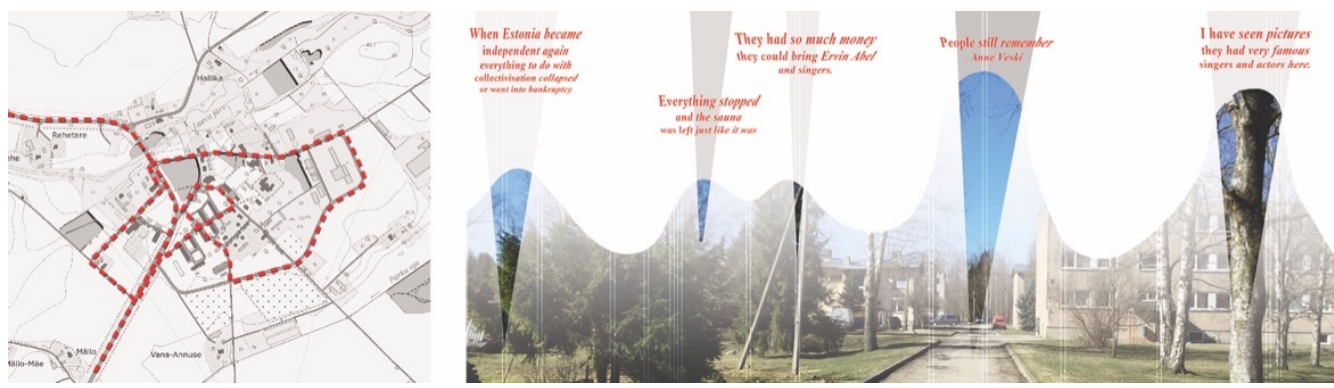

Fig. 5. Go-along conduct in Laeva: Map, route and important quotes. (Source: the authors)

The interviewee mentioned the Sauna as the real manifestation of collectiveness in Laeva:

The communal sauna for women and men from the Soviet times is empty now. When Estonia became independent again, everything to do with collectivisation collapsed or went into bankruptcy. Everything stopped and the sauna was left just like it was (Fig. 6). There was a fire-place with a bar and a little club-room, even a ticket-office. You got your own small closet. Garages and timber industry were here, so it was their relaxing place. It was still functioning in the 1990s.

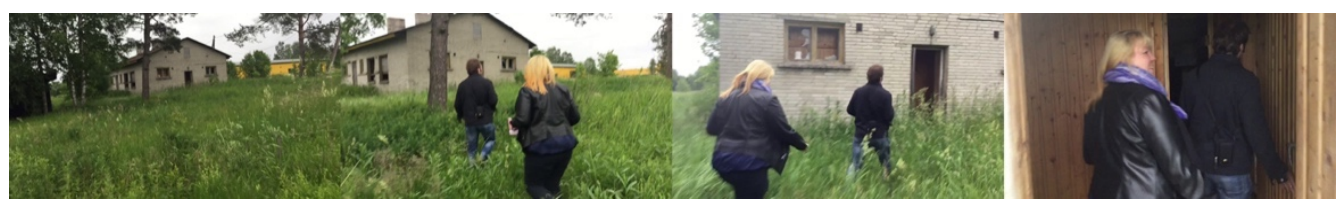

Fig. 6. Stills from the Go-along at the Sauna. (Source: the authors)

Also, the bar and restaurant in Laeva was open until 3 am on weekends: 
The shop and dining-room on the second floor was built in the 1970s and on weekends they were open almost all night. I have seen pictures with famous actors here and everybody came. They had so much money then, they brought the famous comedian Ervin Abel with singers. People still remember the famous singer Anne Veski.

\section{Going along and driving together through Viimsi farm}

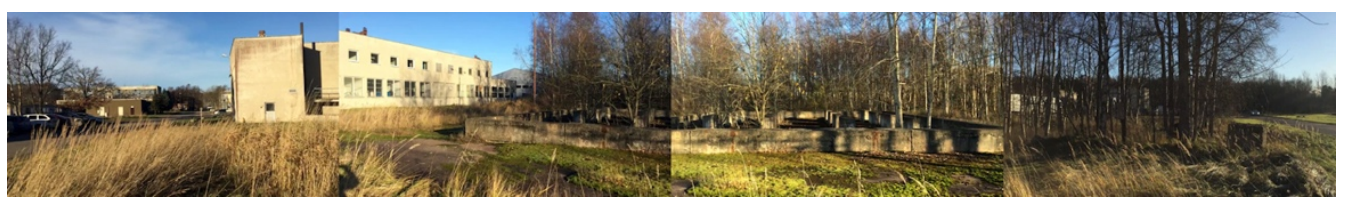

Fig. 7. Look-around in Viimsi. (Source: the authors)

At the former Viimsi (Kirovi) kolkhoz, we spent four hours as four people in a car with Go-along stops, apples from interviewees' garden and with them directing the ride. Viimsi started off as a simple fishing farm, successfully developing into a socialist multibranch company. It was not possible to access the local interviewees memories in a traditional interview because they did not start to talk about certain topics without the triggers of the surrounding landscape. While walking at one stop we pointed to a building that we had already captured in an earlier look-around (Fig. 7). It was really difficult to overlook and we asked both interviewees what they thought of this object:

When Gorbachev came into power in 1985 an Anti-Alcohol Campaign was established, so Viimsi collective had to end the wine industry and somehow came up with the idea to start with shampoo production instead.

\section{Discussion}

The visual exploration of the site and the memories and stories triggered by the Goalong interview helped to reveal the recent history of the landscape (Fig. 8). Kusenbach states that "Encountering personal landmarks during their daily routines frequently evokes feelings of identification and at-homeness in my informants. Often, an aura of nostalgia envelopes their past homes..." [6: 472]. We also found that moving around in their natural environments encouraged interviewees to talk about people they passed and then integrated them into their story. Go-alongs led to unplanned thought processes, such as the emplacement of past experiences which would not appear in a more formal and structured interview set-up.
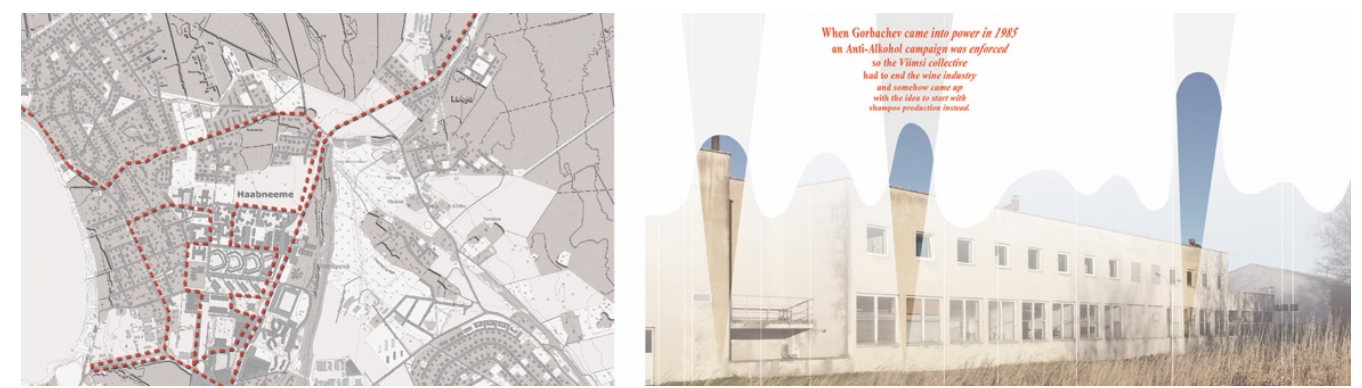

Fig. 8. Go-along conduct in Viimsi: Map, route and important quote. (Source: the authors)

The car gave access to areas that were far away and allowed two researchers to visit more remote fields and farms in one single interview, combined with taking notes 
and pictures while moving. GPS, audio/video recording make it easier to generate, organise and analyse data. Still, Go-alongs need to be combined with more static methods to deepen the understanding or specific concerns, constituting a valuable complement to the traditional expert perspective.

It was an effective tool to gather different perceptions of places from only a limited number of interviewees, because moving along routes had encouraged them to express meanings and values of places. The Go-along interviews have connected past and present together by showing the landscape as it has changed and the ruins to the people who have worked there which fill them with their stories.

\section{Conclusions}

Go-along interviews provide unique access to biographies by taking a spatial versus a chronological approach. "By tracking the natural sequence of places in practical everyday life, Go-alongs enhance our understandings of how individuals connect and integrate the various regions of their daily lives and identities..." [6: 478]. The Go-along interviews illuminated how participants used and understand the different MODSCAPES, by taking the interviewing process out of the room.

What we found is far from being a completely negative period for the people experiencing it, as life in the collective farm was not all bad as noted in the quotations presented here. There were good working conditions for some at least, pride in their achievements and appreciation of a good cultural life, although there were also memories of being amazed at some of the things that were done and how they were done.

\section{Acknowledgements}

MODSCAPES is a collaborative research project funded under the HERA - Humanities in the European Research Area 3rd Joint Research Programme dedicated to "Uses of the Past" (20162019). This project has received funding from the European Union's Horizon 2020 research and innovation programme under grant agreement $n^{\circ} 649307$.

\section{Short resume}

Friedrich Kuhlmann Dipl.-Ing. is a landscape architect and Chief Specialist at the Estonian University of Life Sciences in Tartu, Estonia.

Martti Veldi MSc is an archaeologist and a Junior Researcher at the Estonian University of Life Sciences in Tartu, Estonia. He is also an inspector in the Estonian Heritage board responsible for identifying and protecting cultural heritage monuments.

\section{References}

1. KUHLMANN, F.; BELL, S.; VELDI, M. 2017. Research methods for work package 2: Physical legacies, [Unpublished working paper], MODSCAPES.

2. GEERTZ, C. 1973. The Interpretation of Cultures, New York, Basic Books.

3. VELDI, M.; BELL, S. 2019. "Historical GIS: Application of map-based biography to the Laeva sovkhoz/state farm, Estonia", in S. Bell, A. Fisher, V. Capresi et al. (eds.) Modernism, Modernisation and the Rural Landscape, (Proceedings of the MODSCAPES_2018 conference \& Baltic Landscape Forum, Tartu, Estonia, 11-13 June 2018) Les Ulis, EDP Science (SHS Web Conf., $\mathrm{n}^{\circ}$ 63). DOI: https://doi.org/10.1051/shsconf/20196307001 
4. KUHLMANN, F. 2019. " 'Alive and kicking' - Moving through and diving into the Soviet kolkhoz and the East German LPG", in S. Bell, A. Fisher, V. Capresi et al. (eds.) Modernism, Modernisation and the Rural Landscape, (Proceedings of the MODSCAPES_2018 conference \& Baltic Landscape Forum, Tartu, Estonia, 11-13 June 2018) Les Ulis, EDP Science (SHS Web Conf., $\mathrm{n}^{\circ}$ 63). DOI: https://doi.org/10.1051/shsconf/20196305004

5. PINK, S. 2011. "Multimodality, multisensoriality and ethnographic knowing: social semiotics and the phenomenology of perception", Qualitative Research, vol. 11, n 3: 261-276. DOI: https://doi.org/10.1177/1468794111399835

6. KUSENBACH, M. 2003. "Street phenomenology: the go-along as ethnographic research tool", Ethnography, vol. 4, n 3 : 455-485.

DOI: https://doi.org/10.1177/146613810343007

7. BERGERON, J.; PAQUETTE, S.; POULLAOUEC-GONIDEC, P. 2014. "Uncovering landscape values and micro-geographies of meanings with the goalong method", Landscape and Urban Planning, vol. 122: 108-121.

DOI: https://doi.org/10.1016/j.landurbplan.2013.11.009

8. ZHUKOVA, O.; BELL, S. 2018. "The krushchkevka and the dom kultura: urban lifestyles in a rural setting", in S. Bell, A. Fisher, V. Capresi et al. (eds.) Modernism, Modernisation and the Rural Landscape, (Proceedings of the MODSCAPES_2018 conference \& Baltic Landscape Forum, Tartu, Estonia, 11-13 June 2018) Les Ulis, EDP Science (SHS Web Conf., $n^{\circ} 63$ ).

DOI: https://doi.org/10.1051/shsconf/20196308001 